\title{
Logistics investment model of project evaluation
}

\author{
Nataliya Solonina ${ }^{1}$, Larisa Alekseeva ${ }^{2}$ and Sergei Barykin ${ }^{3 *}$ \\ ${ }^{1}$ Peter the Great St. Petersburg Polytechnic University, Polytechnic Str., 29, Saint-Petersburg, \\ 195251, Russia \\ ${ }^{2}$ St. Petersburg national research University of Information Technologies, Mechanics and \\ Optics (ITMO), Kronverksky Pr-kt, 49, Saint-Petersburg,197101, Russia \\ ${ }^{3}$ St. Petersburg State Marine Technical University, Lotsmanskaya street, 3, Saint-Petersburg, \\ 190121, Russia
}

\begin{abstract}
The purpose of the analytical review consists of the comprehensive socio-economic analysis multi-criteria optimization methods of investment project for investment programs. Those are related to the use of economic and statistical information which could be implemented in identification of consistent patterns in the processes of individual phenomena development in society and in the study of the indicators. The results of the scientific research include the effect of individual factors on abovementioned processes. The importance of innovative development is one of the main indicators of investment under uncertainty, taking into account social orientation of investment program planning in companies. Logistics investment model serves for the purpose of investment process simplification on the basis of logistics processes, which take place in contrast to decomposition of functional areas of logistics and assessment of the investments.
\end{abstract}

\section{Introduction}

The nature and extent of the studied problems is related to the choice of the optimal investment project, which is extremely relevant at present time. Competent and reasonable capital investments are necessary for the sustainable growth of the country's economy, creation of new jobs and increase in the level of welfare of the population.

It should be noted that several criteria are used for the investment project adoption in addition to the traditional integral indicators. Systematic approach considers an investment project in the context of the formation of an innovative economy in Russia. The knowledgebased economy is associated with the transfer of innovation, flow of knowledge, which considers the new theoretical approach to the study of different flows in relation to the concept of an investment project. In the regional projections of investment strategies we can say that the consideration of the available assets stands for the detailed analysis of the contribution to the development of the region. A comprehensive socio-economic analysis can be used as a methodological approach for the formation of a model for assessing the

\footnotetext{
*Corresponding author: sbe@ list.ru
} 
innovative development of the region. The method of complex socio-economic analysis is based on the use of economic and statistical information from previous periods to study changes in indicators, identify patterns in the development of individual phenomena and processes in society, analyze the impact of individual factors on these processes.

Researcher I. V. Somina in the evaluation of innovative development offers such an indicator as the importance [1]. The importance of innovative development of the region, according to the scientist, should be determined by the following formula (1):

$$
I S=\sum_{i=1}^{n} \alpha_{i} \times I_{i}
$$

where $I S$ - General assessment of the importance of individual innovative characteristics of the region; $n$ - the number of estimated elements that determine the main parameters of innovation in the region; $I_{i}$ - the $i$-th parameter of regional innovation development the $i$-th parameter of regional innovation development; $\alpha_{i}-$ the coefficient of significance of the $i$-th parameter of the innovation environment in the integrated assessment $\left(\sum_{i=1}^{n} \alpha_{i}=1\right)$.

\section{Materials and Methods}

The study relates to the integrated structures (business groups and large companies) taking into account all aspects of the enterprise, the importance of investment areas, economic, technical and environmental aspects of projects [2]. One of the priority tasks for Russia is the development of electric power distribution networks, which can be accomplished with the help of models and methods of logistics theory. The method of formation of the investment program of the distribution network company can be formed on the basis of the logistic approach that allows to choose capital investment options on the basis of the multipurpose analysis of efficiency of investments in the conditions of uncertainty taking into account the social orientation of investment program planning in the company [2].

For example, we present the problem of investment strategy selection of projects distributed in the areas of investment. The decision can be made both by the private investor, and from the position of the credit institution considering prospects of investment. It is possible to consider alternative investment projects, assuming that you should invest only in one of the objects under consideration, or to rank the objects according to the degree of importance for the investor.

The definition of the overall goal is the distribution of investment projects in order of importance. Therefore the level of capital investment group of projects in accordance with the nature of construction and capital investment structure can be the following:

1) new construction projects; 2) adding new construction facilities that are not part of new construction projects (so-called expansion of production capacity); 3) reconstruction; 4) technical re-equipment; 5) maintenance of capacity; 6) construction of individual facilities that could not be considered as all capital investments mentioned above.

Determination of the most important criteria considers that there could be criteria that evaluate investment projects from an economic, technical, environmental and risk perspective. Social orientated concept is considered by professor Kalinina innovative approach to macroeconomic models [12].

In case of a large number of investment programs (more than 7), it is recommended to group the alternatives into clusters according to their relative importance. It is possible to form a cluster of investment projects with a high degree of superiority, moderate importance and low importance relative to the criterion under consideration [3, 4].

The problem of choosing the optimal investment project in accordance with criteria under consideration can be presented in Fig. 1. 


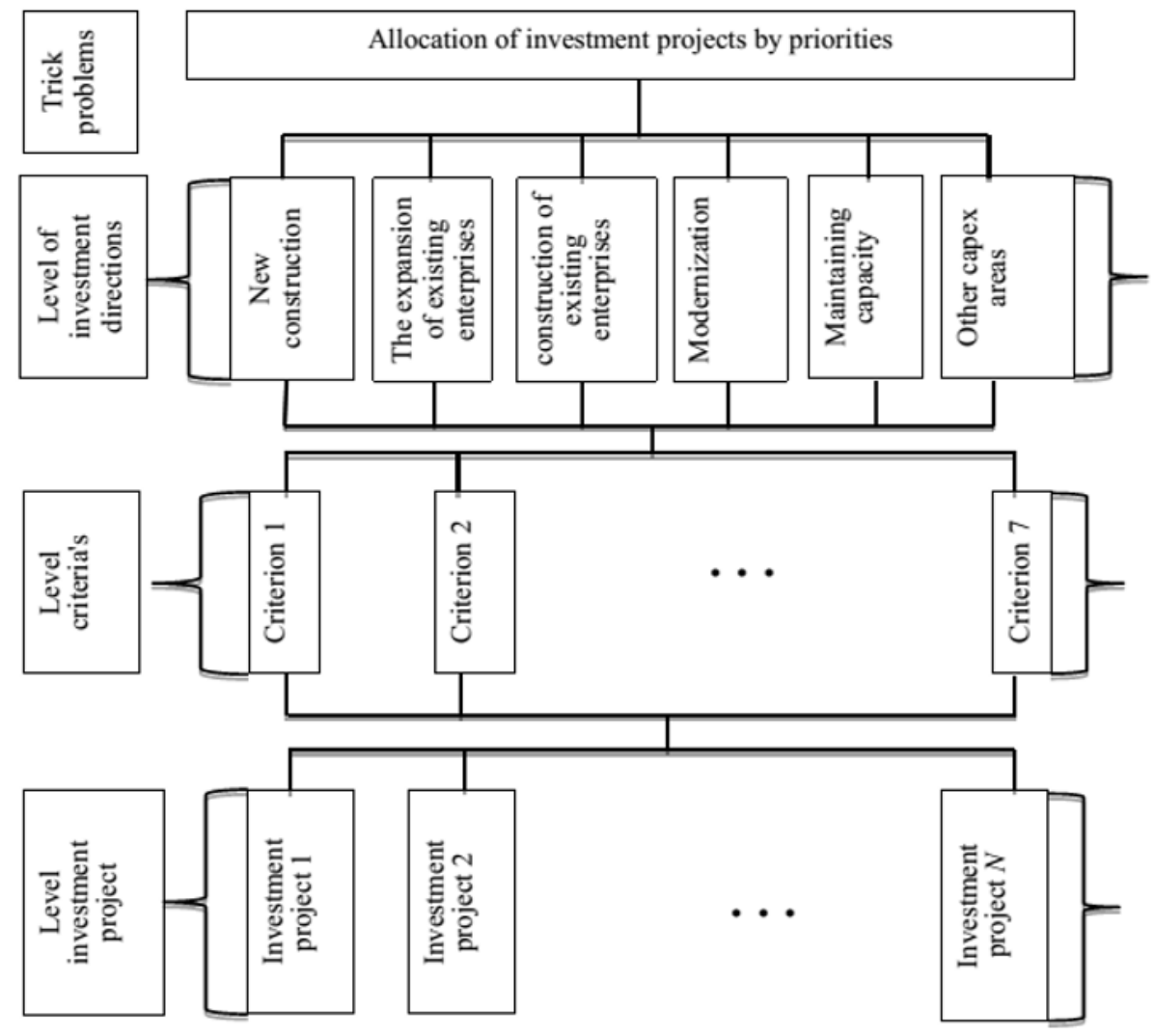

Fig. 1. Decomposition of the problem of investment projects selection, providing the greatest contribution to the achievement of the goals set

V. V. Tkach, when considering the identification of elements of the logistics system and characterizing the place and role of logistics in the organization of commercial activities of industrial enterprises, notes that the increasing need for logistics today is so great that the need to reduce logistic costs is thus becoming one of the imperatives [5]. Long-term investments in logistic systems are viewed in the context of assessing and comparing their future cash flows. In addition, it is widely believed that the adoption of the logistics concept enhances the investment process. Functional requirements for integrated design of logistics processes in this activity, according to [6] - is the elimination of "bottlenecks" in the logistics system (HP) and simplification of integration and optimization of logistics processes that take place in contrast to decomposition of functional areas of logistics processes and operations. The latter circumstance serves for the purposes of investment design, and this model creates objective prerequisites for an accurate assessment of the required investments in the development of the logistics system.

Despite the urgency of the problem of choosing an investment project, a single universal solution to the problem of choosing the most attractive project has not been found [7, 8]. The most banks use their own proprietary project selection methodologies, and smaller organizations often rely on the intuition and talent of managers.

Two possible optimization approaches to the problem of making investment decisions are considered in this article, their analysis is carried out and a new method for solving this problem is proposed. 


\section{Results}

The study has found that nontraditional integrated indicators should be used as criteria in new method of selecting the most effective investment project. Hereafter the authors consider only the commercial efficiency of the project and do not consider its social significance.

Traditional integral indicators of investment project efficiency are the following [9]:

1. NPV-Net Present Value.

Present value of future cash flows of the investment project, calculated on the basis of discounting, net of investments.

$$
N P V=\sum_{t=0}^{n} \frac{C F_{t}}{(1+r)^{t}}-\sum_{t=0}^{n} \frac{I_{t}}{(1+r)^{t}}
$$

where $r$-discount rate, $n$ - project duration, $C F_{t}$ - result of operating cash flows in the period $t, I_{t}$-investments in the period $t$.

2. PI-Profitability Index.

The profitability index, which is more reasonably called the discounted profitability index, is calculated as the ratio of discounted returns on investments to the value of investments caused them.

3. DPP-Discounted Payback Period.

$$
P I=\frac{\sum_{t=0}^{n} \frac{C F_{t}}{(1+r)^{t}}}{\sum_{t=0}^{n} \frac{I_{t}}{(1+r)^{t}}},
$$

The payback period is, by definition, the time period necessary for investment income adjusted to the present time, covering the cost of investment.

The payback period is from the condition:

4. IRR - Internal Rate of Return.

$$
\sum_{t=0}^{D P P} \frac{C F_{t}}{(1+r)^{t}}>\sum_{t=0}^{n} \frac{I_{t}}{(1+r)^{t}}
$$

$I R R$ - is a discount rate, which equates the investments made and the expected revenues for the project. The equation for finding IRR:

5. ARR - Accounting Rate of Return.

$$
N P V(I R R)=\sum_{t=0}^{n} \frac{C F_{t}}{(1+I R R)^{t}}-\sum_{t=0}^{n} \frac{I_{t}}{(1+I R R)^{t}}=0
$$

ARR is calculated as the average profit from the project for the period to the investments that caused this profit.

$$
A R R=\frac{\frac{\sum_{t=0}^{n} C F_{t}}{n}}{\sum_{t=0}^{n} I_{t}}
$$

None of the above criteria alone is sufficient for the adoption of the draft. The decision to invest in the project should take into account the values of all these criteria and the interests of all participants in the investment program. The structure and timing of the capital raised for the project, as well as other factors, some of which are only amenable to substantive (rather than formal) accounting, should play an important role in this decision. 
For the maximum possible objective assessment of investments, it is desirable to use a model that includes all the above indicators, so the answer to the question about the optimal project is advisable to look in the field of multi-criteria optimization.

The paper [10] provides statistical data that shows which indicators of investment analysis are used more often and which are less frequently. In this method (hereinafter referred to as the Yuriev method) optimization is proposed to produce three indicators that are average in frequency of use. According to this method, as the criteria are taken for the NPV, DPP and PI.

We introduce the following notations:

$i-$ criterion number $(i=1, \ldots, 3))$;

$\left\{x_{j}\right\}$ - many alternative investment projects;

$j$ - alternative business project number $(j=1, \ldots, m)$.

It is necessary to use three criteria to choose from a set of $\left\{x_{j}\right\}$ alternative investment projects such an optimal project $X_{j}^{*}$, which would meet the following requirements:

$$
\begin{aligned}
& (j=1, . ., m) \\
& N P V=\left(X_{j}^{*}\right) \rightarrow \max . \\
& 1 / D P P=\left(X_{j}^{*}\right) \rightarrow \max . \\
& P I\left(X_{j}^{*}\right) \rightarrow \max .
\end{aligned}
$$

The objective function (1) reflects the requirement to maximize $N P V$, the objective function (2) implies the need to ensure a minimum DPP of the project, and the objective function (3) reflects the requirement to maximize $P I$.

Due to three criteria, it is necessary to create a common target function that takes into account all three criteria, to make the criteria additive. However, the criteria of NPV, DPP and PI have different economic nature and different units of measurement. Therefore, the first step is the normalization procedure, that is, the criteria are reduced to dimensionless units. To do this, use the function

$$
f_{i j}=\frac{f_{i}\left(x_{j}\right)-f_{i}^{\min }}{f_{i}^{\max }-f_{i}^{\min }},
$$

where $f_{i j}$ - normalized value of the $i$-th criterion for the $j$-th business project; $f_{i}\left(x_{j}\right)$ initial value of the $I$-th criterion for the $j$-th business project; $f_{i j}^{\min }, f_{i j}^{\max }$-accordingly, the minimum and maximum value of the $I$-th criterion on the set of projects under consideration $\left(x_{j}\right)$.

Further solution is carried out by the method of uniform optimization, which assumes the equivalence of all criteria. Thus, the project with the highest value of the objective function is considered optimal $R_{j}$ :

$$
R_{j}=\sum_{i=1}^{3} f_{i j} .
$$

In the method of investment analysis being developed by Grechishkina and Ivakhnik [11] (hereafter Grechishkina - Ivakhnik method) the optimization is performed on the five integral factors: $N P V, P I, D P P, I R R$ and $A R R$. The authors use another method of multicriteria optimization known as the ideal point method.

First, the normalization is carried out according to the formula different from (4):

$$
f_{i j}=\frac{f_{i}\left(x_{j}\right)}{\max _{j} f_{i}\left(x_{j}\right)}
$$


The objective function, which can also be called the project rating, is the Euclidean distance of each project from the ideal point $(1,1 \ldots, 1)$ as follows:

$$
R_{j}=\sqrt{K_{1}\left(1-f_{1 j}\right)^{2}+K_{2}\left(1-f_{2 j}\right)^{2}+\ldots+K_{5}\left(1-f_{5 j}\right)^{2}},
$$

where $K_{1}, K_{2}, \ldots K_{5}$ - expert coefficients assigned by the investor.

In accordance with the method of the ideal point, it is further necessary to find

$$
\min _{j} R_{j}
$$

The above methods have a number of advantages and disadvantages.

\section{Discussion}

During a discussion of methods mentioned above, let us return to the Yuriev method, this method is good in terms of simplicity of calculations, but, at the same time, has a number of disadvantages. The first, and most important, is the inclusion of an insufficient number of criteria. It is easy to see in table 1 that the most authoritative and used indicator is the internal rate of return (IRR). Its inclusion in the calculation formula adds the ability to compare projects of different scale.

Grechishkina - Ivakhnik method considers all the criteria and, subject to peer ratios, allows to identify the most important ones from the point of view of the investor. This should be used when the key factor is the time, that is, more attention is paid to the time of return of invested funds. In this case, the increase in the significance of this factor in the final formula is achieved by increasing the corresponding coefficient. However, this method has a large computational complexity. In addition, none of the above methods take into account the fact that it is almost impossible to attract funding in the absence of own funds. In project financing very often you can find the minimum required amount of own funds invested in the project directly by the initiator of the project (recipient). Usually, the level of investment of own funds is required at least $30 \%$.

It is difficult to overestimate the importance of investing own funds. First, the invested own funds make the borrower more responsible and less risky to implement the project. Secondly, to a large extent, it is the introduction of own funds that does not allow the initiator of the project at some point in time to abandon the project, since in this case it bears losses. This is especially important in construction, when the security for the loan is usually the construction itself. For example, the construction of energy facilities should take into account the long period of use of such facilities and the impossibility of their conversion. The construction of such facilities is usually carried out on credit funds, and the pledge on loans for which these facilities are built, as a rule, are the energy facilities themselves. Immediately after the sports event, the recipient, if the level of investment of its own funds did not reach the required level, it may be more profitable to refuse to service the loan, and transfer the collateral to the lender. This creates a dangerous situation when the borrower loses only an unnecessary object, and the credit institution receives an expensive non-core asset on the balance sheet. This example clearly emphasizes the need for the initiator of the project to invest his own funds and, consequently, to study in detail the list of optimization criteria for making investment decisions.

The inclusion of an additional coefficient, the so-called financial independence Coefficient, in the model can reduce this kind of risk - CFI.

The percentage of equity invested in the project to the total cost of the project will be called the coefficient of financial independence $-C F I$.

$$
C F I=\sum_{t=0}^{n} \frac{O A_{t}}{(1+r)^{t}} / \sum_{t=0}^{n} \frac{I_{t}}{(1+r)^{t}},
$$


where $O A_{t}$ - recipient's own funds invested in the project in the period $t$.

Thus, the project for which $C F I$ is close to the unit will be called absolutely financially independent. With the desire of CFI to zero, the riskiness of investments will increase, and the project itself will move into the area of risky. In this paper we propose a generalized method, which includes all the five integral indicators of the project: NPV, PI, IRR, DPP, $\mathrm{ARR}$, and $C F I$.

The normalization procedure remains the same (4), only the number of criteria changes.

In order to give the investor the opportunity to highlight the most important criteria for him, the objective function of the expert are added coefficients, by analogy with the Grechishkina - Ivakhnik method. The objective function takes the form:

$$
R_{j}=\sum_{t=1}^{6} K_{i} * f_{i j} \rightarrow \max \left(\forall_{j}\right)
$$

where $K_{i}$ - expert coefficient for the $i$-th criterion; $j$ - project number; $f_{i j}$ - normalized value of the $i$-th criterion for the $j$-th project.

\section{Conclusions}

As a result, a generalized method is obtained, which is simple to calculate, but includes all main integrated indicators, and also takes into account the risk of not diversified financing.

To study the described methods and implement the developed method, the $C$ language is used. The input of this program receives a CSV file, which is compiled in Microsoft EXCEL or similar spreadsheets. The input file is a table of the following form (table 1):

Table 1. The table contained in the incoming the input to a program in a CSV file

\begin{tabular}{|c|c|c|c|}
\hline \multirow{2}{*}{ INDICATORS } & \multicolumn{3}{|c|}{ Projects } \\
\hline & $\mathrm{x} 1$ & & $\mathrm{x}$ \\
\hline $1 / \mathrm{DPP}, 1$ for a number of years & 0,25 & $\ldots$ & 0,67 \\
\hline ARR, \% & 55,0 & $\ldots$ & 23,3 \\
\hline NPV, monetary units & 557,9 & $\ldots$ & 198,0 \\
\hline PI & 1,46 & $\ldots$ & 0,96 \\
\hline IRR, \% & 22,7 & $\ldots$ & 18,1 \\
\hline CFI & 0,5 & $\ldots$ & 0,7 \\
\hline
\end{tabular}

The output of the program provides information about the optimal investment project for each technique. As a result of numerous experiments, the projects that best illustrate the features of different methods are selected. Performance indicators of these projects are shown in table. 2. As can be seen from the initial data, there is no such project that would be optimal for all criteria, but the project number 12 is optimal for four criteria (ARR, PI, IRR and CFI). In bold in the table 2 optimum projects are allocated. The solution of this problem is carried out by the methods of multi-criteria optimization considered above.

Table 2. Source data table

\begin{tabular}{|l|c|c|c|c|c|c|c|c|c|c|c|c|}
\hline \multirow{2}{*}{\multicolumn{1}{|c|}{ INDICATORS }} & \multicolumn{10}{|c|}{ Projects } \\
\cline { 2 - 14 } & $\mathrm{X}_{1}$ & $\mathrm{X}_{2}$ & $\mathrm{X}_{3}$ & $\mathrm{X}_{4}$ & $\mathrm{X}_{5}$ & $\mathrm{X}_{6}$ & $\mathrm{X}_{7}$ & $\mathrm{X}_{8}$ & $\mathrm{X}_{9}$ & $\mathrm{X}_{10}$ & $\mathrm{X}_{11}$ & $\mathrm{X}_{12}$ \\
\hline $\begin{array}{l}\text { 1/DPP, 1 for a number of } \\
\text { years }\end{array}$ & 0.5 & $\mathbf{2 . 4}$ & 2.2 & 2 & 1.8 & 1.6 & 1.4 & 1.2 & 1 & 0.8 & 0.6 & 0.4 \\
\hline ARR, \% & 30 & 40 & 41 & 42 & 43 & 44 & 45 & 46 & 47 & 48 & 49 & $\mathbf{5 0}$ \\
\hline NPV, thousand \$ & 380 & 480 & 490 & 500 & 510 & 520 & 530 & $\mathbf{6 0 0}$ & 590 & 580 & 570 & 560 \\
\hline PI & 1.46 & 2.46 & 2.56 & 2.66 & 2.76 & 2.86 & 2.96 & 3.06 & 3.16 & 3.26 & 3.36 & $\mathbf{3 . 4 6}$ \\
\hline IRR, \% & 17.1 & $\mathbf{2 7}$ & 26.8 & 18.6 & 26.4 & 26.2 & 26 & 18.2 & 26.4 & 19.6 & 26.8 & $\mathbf{2 7}$ \\
\hline CFI & 0.2 & 0.22 & 0.24 & 0.26 & 0.28 & 0.3 & 0.32 & 0.34 & 0.36 & 0.38 & 0.4 & $\mathbf{0 . 4 2}$ \\
\hline
\end{tabular}


Further, according to the method of calculation, normalization is carried out. It should be noted that the method of rationing the initial data by formulas (4) or (5) does not affect the solution of the optimization problem, only a set of criteria plays an important role. Below are the results of the normalization procedure: in table 3 - according to the Grechishkina - Ivakhnik method and table 4 - according to the Yuriev method and the generalized method.

Table 3. Table of normalized values for the Grechishkina - Ivakhnik method

\begin{tabular}{|l|l|l|l|l|l|l|l|l|l|l|l|l|}
\hline INDICATORS & $\mathrm{X} 1$ & $\mathrm{X} 2$ & $\mathrm{X} 3$ & $\mathrm{X} 4$ & $\mathrm{X} 5$ & $\mathrm{X} 6$ & $\mathrm{X} 7$ & $\mathrm{X} 8$ & $\mathrm{X} 9$ & $\mathrm{X} 10$ & $\mathrm{X} 11$ & $\mathrm{X} 12$ \\
\hline $\begin{array}{l}\text { 1/DPP, 1 for a number of } \\
\text { years }\end{array}$ & 0.21 & 1 & 0.92 & 0.83 & 0.75 & 0.67 & 0.58 & 0.5 & 0.42 & 0.33 & 0.25 & 0.17 \\
\hline ARR, \% & 0.6 & 0.8 & 0.82 & 0.84 & 0.86 & 0.88 & 0.9 & 0.92 & 0.94 & 0.96 & 0.98 & 1 \\
\hline NPV, thousand \$ & 0.63 & 0.8 & 0.82 & 0.83 & 0.85 & 0.87 & 0.88 & 1 & 0.98 & 0.97 & 0.95 & 0.93 \\
\hline PI & 0.42 & 0.71 & 0.74 & 0.77 & 0.8 & 0.83 & 0.86 & 0.88 & 0.91 & 0.94 & 0.97 & 1 \\
\hline IRR, \% & 0.63 & 1 & 0.99 & 0.99 & 0.68 & 0.97 & 0.96 & 0.67 & 0.98 & 0.73 & 0.99 & 1 \\
\hline
\end{tabular}

Table 4. Table of normalized values for the Yuriev method and generalized method

\begin{tabular}{|l|l|l|l|l|l|l|l|l|l|l|l|l|}
\hline INDICATORS & $\mathrm{X} 1$ & $\mathrm{X} 2$ & $\mathrm{X} 3$ & $\mathrm{X} 4$ & $\mathrm{X} 5$ & $\mathrm{X} 6$ & $\mathrm{X} 7$ & $\mathrm{X} 8$ & $\mathrm{X} 9$ & $\mathrm{X} 10$ & $\mathrm{X} 11$ & $\mathrm{X} 12$ \\
\hline $\begin{array}{l}\text { 1/DPP, 1 for a number of } \\
\text { years }\end{array}$ & 0.05 & 1 & 0.9 & 0.8 & 0.7 & 0.6 & 0.5 & 0.4 & 0.3 & 0.2 & 0.1 & 0 \\
\hline ARR, \% & 0 & 0.5 & 0.55 & 0.6 & 0.65 & 0.7 & 0.75 & 0.8 & 0.85 & 0.9 & 0.95 & 1 \\
\hline NPV, thousand \$ & 0 & 0.45 & 0.5 & 0.55 & 0.59 & 0.64 & 0.68 & 1 & 0.95 & 0.91 & 0.86 & 0.82 \\
\hline PI & 0 & 0.5 & 0.55 & 0.6 & 0.65 & 0.7 & 0.75 & 0.8 & 0.85 & 0.9 & 0.95 & 1 \\
\hline IRR, \% & 0 & 1 & 0.98 & 0.96 & 0.13 & 0.92 & 0.90 & 0.11 & 0.94 & 0.25 & 0.98 & 1 \\
\hline CFI & 0 & 0.5 & 0.55 & 0.6 & 0.65 & 0.7 & 0.75 & 0.8 & 0.85 & 0.9 & 0.95 & 1 \\
\hline
\end{tabular}

The generalized method uses the same normalization procedure as the Yuriev method. Hence, the table of normalized coefficients of the generalized method contains a table of normalized coefficients of the Yuryev method. Note that the value "1" in the table 3 and 4 show achievement of optimum value of this criterion on the corresponding project, and " 0 " in table 4 means the minimum value of the criterion. The next step is to calculate the final rating values for each method. In this paper, the problem of determining the dependence of the final result on the value of the expert coefficients is not posed, therefore, all expert coefficients in this calculation are taken to be equal to one. The final rating values are calculated for each of the three methods. Table 5 shows the ratings of projects for all three methods of calculating the investment efficiency of the project. Optimal projects are highlighted in bold. It should be noted, the Grechishkina - Ivakhnik method uses the optimal point method, so a project with a minimum rating value (7) is selected for it.

Table 5. The outcome ratings of projects

\begin{tabular}{|c|c|c|c|}
\hline Projects & Yuriev's Method & $\begin{array}{c}\text { Grechishkin - } \\
\text { Ivakhnik method }\end{array}$ & $\begin{array}{c}\text { Generalized } \\
\text { method }\end{array}$ \\
\hline $\mathrm{X}_{1}$ & 0.05 & 1.64 & 0.05 \\
\hline $\mathrm{X}_{2}$ & 1.954 & 0.7 & 3.95 \\
\hline $\mathrm{X}_{3}$ & 1.9500 & 0.669 & 4.02 \\
\hline $\mathrm{X}_{4}$ & 1.945 & $\mathbf{0 . 6 6 4}$ & 4.10 \\
\hline $\mathrm{X}_{5}$ & 1.94 & 0.869 & 3.37 \\
\hline $\mathrm{X}_{6}$ & 1.936 & 0.72 & 4.25 \\
\hline $\mathrm{X}_{7}$ & 1.931 & 0.77 & 4.33 \\
\hline $\mathrm{X}_{8}$ & $\mathbf{2 . 2}$ & 0.96 & 3.91 \\
\hline $\mathrm{X}_{9}$ & 2.1 & 0.85 & 4.74 \\
\hline $\mathrm{X}_{10}$ & 2.0 & 1.01 & 4.06 \\
\hline $\mathrm{X}_{11}$ & 1.91 & 0.94 & 4.79 \\
\hline $\mathrm{X}_{12}$ & 1.81 & 0.98 & $\mathbf{4 . 8 1}$ \\
\hline
\end{tabular}


As can be seen from the results (table 5), all the considered methods have led to different choices of the optimal investment project. For the generalized method, the strong influence of the financial independence coefficient is noticeable (see Fig. 2).

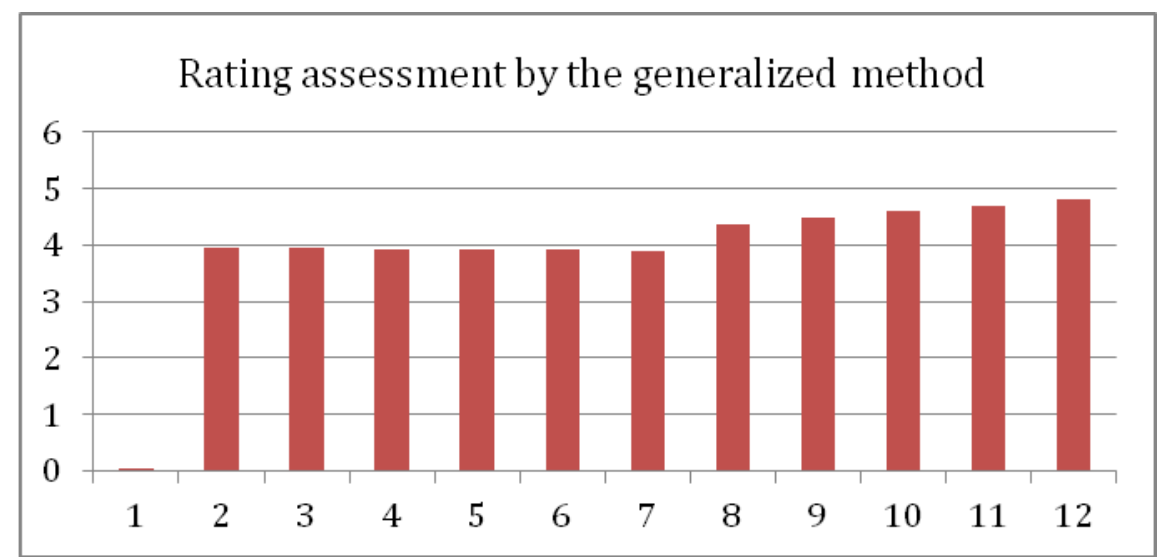

Fig. 2. Rating estimation by generalized method

The coefficient of financial independence increases linearly with the increase of the project sequence number. The optimal investment project from the point of view of the generalized method is project No. 12, for which a maximum of four criteria is achieved, and the ratio of borrowed funds to own funds is the lowest. Thus, the least risky project is chosen.

Grechishkina - Ivakhnik method coming from the minimal deviations from the ideal project shows that the optimum project № 4. This can be explained by the fact that project No. 4 has no strong deviations from the maximum values for any of the criteria under consideration. But for the provision of financing is usually used the necessary level of equity of not less than $30 \%$, and the project number 4 does not meet this condition, so it will be difficult to find a potential investor.

Selection according to the method of St. George leads in this case to the choice of the project with the highest NPV index (project № 8). In addition to the high NPV index, project No. 8 is also characterized by a low IRR value, which shows the maximum profitability of the project for its entire life cycle. Thus, this project is least protected from risks, for example, associated with inflation. According to the results of this experiment, it can be concluded that the generalized method chooses the least risky project, the Grechishkina - Ivakhnik method allows to select the project averaged by all criteria, and the Yuryev method takes into account not a sufficient number of criteria and is therefore unrealistic. The generalized method solves the problem of reducing investment risks and is particularly appropriate for use in tenders for participation in national programs with a large share of subsidies from state budgets. The use of the developed mathematical model of investment decision-making will also allow to get rid of the corruption component during tenders and issuance of investment loans.

\section{References}

1. I.V. Ilin, V.I. Koposov, A.I. Levina, Model of asset portfolio improvement in structured investment products, Life Science Journal, 11, 265-269 (2014)

2. I.V. Ilin, O. Kalinina, O. Iliashenko, A. Levina, Procedia Engineering, 165, 1683 1692 (2016) DOi- 10.1016/j.proeng.2016.11.910 
3. V.V. Gluhov, I.V. Ilin, V.I. Koposov, A.I. Levina, Asian Social Science, 10 (24), 209216 (2014) DOi- 10.5539/ass.v10n24p209

4. I.V. Ilin, A.I. Levina, O.Yu. Iliashenko, Advances in Intelligent Systems and Computing, 692, 1214-1223 (2018) DOi -10.1007/978-3-319-70987-1_130

5. I.V. Ilin, A. Lepekhin, A.I. Levina, O.Yu. Iliashenko, Advances in Intelligent Systems and Computing, 692, 1306-1314 (2018) DOi -10.1007/978-3-319-70987-1_138

6. I.V. Ilin, A.I. Levina, O.Yu. Iliashenko, MATEC Web of Conf., 106, 08066 (2017) DOi-10.1051/matecconf/201710608066

7. I.V. Ilin, O.Yu. Iliashenko, A.I. Levina, Application of service-oriented approach to business process reengineering, Proc. of the 28th IBIMA Conf. - Vision 2020, 768781 (2016)

8. I.V. Ilin, A.B. Anisiforov, Improving the efficiency of projects of industrial cluster innovative development based on enterprise architecture model, WSEAS Transactions on Business and Economics, 11, 757-764 (2014)

9. V.V. Gluhov, I.V. Ilin, Lecture Notes in Computer Science, 8638, 509- 518, (2014) DOi-10.1007/978-3-319-10353-2_46

10. I.V. Ilin, A.I. Levina, O.Yu. Iliashenko, MATEC Web of Conf, 86, 05028 (2016) DOi - 10.1051/matecconf/20168605028

11. I Ilin, O. Kalinina, O. Iliashenko, A. Levina, Procedia Engineering, 165, 1673- 1682 (2016) DOi - 10.1016/j.proeng.2016.11.909

12. I Zaychenko, S. Gutman, O. Kalinina, Advances in Intelligent Systems and Computing, 692, 453-462 (2018) DOi - 10.1007/978-3-319-70987-1_48 